\title{
Food Partitioning in Three Syntopic Frogs in a Bornean Plantation
}

\author{
MASAFUMi MATSUI* \\ Graduate School of Human and Environmental Studies, Kyoto University, \\ Yoshida Nihonmatsu-cho, Sakyo-ku, Kyoto 606-8501, JAPAN
}

\begin{abstract}
In the Brumas Plantation, Tawau, eastern Sabah of Borneo Island, I examined stomach contents of three frog species that are apparently segregating in microhabitat and morphology; Limnonectes cf. kuhlii is riparian, very stocky and always staying near streams or pools; Amnirana niobariensis, with slim body and long limbs, is terrestrial, inhabiting bushes near small pools, and Polypedates macrotis is arboreal, possessing large digital discs, and is found on trees or tall grasses. These three frog species exhibited food partitioning, differing in the amount and size of foods. Young $L$. cf. $k$ khlii always had stomach content mass (SCM) up to $3 \%$ of body mass (BM), and had the largest average number of small food items. In adult $L$. cf. kuhlii, few individuals lacked stomach contents, and foods were generally larger than in young frogs. Many $A$. nicobariensis had no stomach contents, and those with foods usually possessed SCM $<2 \%$ of BM. Most food items were small in length. Polypedates macrotis tended to take large foods, but many had empty stomachs. Limnonectes cf. kuhlii and $P$. macrotis exhibited the mean food length smaller than their mouth width. When all frogs were combined, ants occupied the largest portion of all the food items, followed by crickets or grasshoppers, beetles, and spiders in that order.
\end{abstract}

Key words: Borneo; Food segregation; Plantation forest; Sabah; Syntopic anurans

\section{INTRODUCTION}

Frogs and toads, like lizards and birds, are regarded as an eminent natural enemy of many kinds of small invertebrate animals, and are thought to contribute much in controlling the number of insects, possibly including pest species (Hocking and Babbitt, 2014). The

Tel/Fax: +81-75-642-8072;

E-mail address: fumi@zoo.zool.kyoto-u.ac.jp

* Present address: Fukakusa Bo-cho 12-13,

Fushimi-ku, Kyoto 612-0871, JAPAN frogs and toads of Sabah, in the Malaysian part of Borneo Island, were investigated earlier than those of other regions of Southeast Asia (e.g., Inger, 1966, 1985; Matsui, 1979, 1982, 1986), and are also intensively studied at present (e.g., Matsui et al., 2010, 2013, 2014a, b). However, most of the studies are largely or strictly confined to their taxonomy and systematics (Matsui, 2006): other aspects of anuran amphibians of Sabah, as well as of the remaining parts of Southeast Asia, have been less intensively studied, although previous studies on the anurans of Borneo include a few important ecological investigations 
(e.g., Inger and Greenberg, 1966; Inger and Bacon, 1968; Inger, 1969). Compared with frogs and toads of the neotropical (e.g., Toft, 1980, 1981) and temperate Asian regions (e.g., Hiari and Matsui, 1999, 2000a, b, 2002), the tropical Asian species have been poorly examined for feeding biology.

The aim of the present investigation is to obtain basic data for a better understanding of prey/predator relationships between small invertebrates and anurans in the cultivated tropical rain forest. To pursue this, I made an analysis of stomach contents of three common frog species from the Brumas plantation area in eastern Sabah.

\section{Materials And Methods}

I made a survey between 20 and 29 September 1985 around the Cocoa plantation at the Brumas Plantation, Sabah Softwoods Sdn. Bhd., Tawau, eastern Sabah of Borneo Island (East Malaysia). Frogs were collected in the following five stations during 1830$2030 \mathrm{~h}$, when light trap collections of forest insects were made: 1) Cocoa plantation, 2) Albizia plantation, 3) Gmelina plantation, 4) Acacia plantation, and 5) secondary forest surrounding the plantation area. Collection was made by hand or with a dip net.

Individual frogs were preserved within $1 \mathrm{~h}$ after capture in $10 \%$ commercial formalin, and within two months, they were measured, dissected for identifying sex and maturity, and had their stomach contents studied. Sex and states of maturation were determined by the size of oviducts and ovaries, and the presence or absence of secondary sex characters. Measurements were taken for snout to vent length (SVL), mouth width (MW), and tibia length (TL) in each of these formalinpreserved specimens to nearest $0.1 \mathrm{~mm}$ with dial calipers. Frogs were wiped with paper towel and individual body mass (BM) was measured with a balance to the accuracy of $1 \mathrm{mg}$. Stomachs were removed and dissected under a stereoscopic binocular microscope. The difference in stomach mass before and after the removal of contents was taken as the mass of stomach content mass (SCM). Stomach contents were identified and counted, and the length and width of each item were measured. If part of a food item was already digested, the original size was estimated with reference to the intact specimens of identical or related species (cf. Hirai and Matsui, 2001). Frogs were later transferred to $70 \%$ ethanol and stored in the collection of Graduate School of Human and Environmental Studies, Kyoto University (KUHE).

Since the three frog species, Limnonectes cf. kuhlii, Amnirana nicobariensis, and Polypedates macrotis, were most common in the Brumas plantation area (see results), detailed examinations of stomach contents were restricted to them. Also, since the number of samples was small, data from the five types of forests (see above) were combined. The three species are regarded as ideal for such analyses since they are quite divergent in morphology and ecology. Amnirana nicobariensis is a slim-bodied frog with long limbs, and is terrestrial, inhabiting bushes near small pools. Limnonectes cf. kuhlii is riparian in its habit and always stays near streams or pools. Contrasting to the slim body of $A$. nicobariensis, the body of $L$. cf. kuhlii is very stocky. Polypedates macrotis is an essentially arboreal species and is found on trees or tall grasses. Thus, these three species are apparently segregating their microhabitats.

\section{RESUlTS}

\section{Frog fauna}

Fifteen species of frogs and toads belonging to five families were recorded during the survey (Table 1). Of the five stations surveyed, the Acacia plantation was richest in the anuran fauna and nine of those 15 species $(60 \%)$ were found there. This is probably because of the presence of a large river near the station. On the contrary, only four of the total 15 species $(26.7 \%)$ were obtained from the Gmelina plantation. The remaining three stations were similar to each other in the 
TABLE 1. List of frogs and toads collected in the Brumas area. St.1=Cocoa plantation; St.2=Albizia plantation; St. $3=$ Gmelina plantation; St.4=Acacia plantation; St. $5=$ secondary forest. "+" indicates the presence of the species.

\begin{tabular}{llccccc}
\hline Family & Species & St. 1 & St. 2 & St. 3 & St. 4 & St. 5 \\
\hline \multirow{2}{*}{ Bufonidae } & Phrynoidis asper & - & - & - & + & - \\
& Ingerophrynus divergens & + & - & - & - & - \\
& Ansonia spinulifer & - & - & - & + & - \\
Microhylidae & Kaloula baleata & - & + & - & - & - \\
Ranidae & Amnirana nicobariensis & + & + & + & + & + \\
& Chalcorana raniceps & - & - & + & + & + \\
& Pulchrana signata & - & - & - & - & + \\
Dicroglossidae & Limnonectes cf. kuhlii & + & + & - & + & + \\
& Limnonectes finchi & - & - & - & + & - \\
& Occidozyga laevis & + & + & - & - & - \\
Rhacophoridae & Polypedatus otilophus & - & - & - & - & + \\
& Polypedates macrotis & + & + & + & + & + \\
& Rhacophorus fasciatus & - & + & - & - & - \\
& Rhacophorus pardalis & + & - & - & + & - \\
& Kurixalus appendiculatus & + & + & - & + & - \\
\hline
\end{tabular}

faunal diversity of frogs and toads. Amnirana nicobariensis and $P$. macrotis were abundant in all places surveyed. Limnonectes cf. kuhlii was also found at all stations except in the Gmelina plantation.

\section{Amount of contents in the stomach of three species}

As a result of dissection, a total of 53 frogs proved to consist of 11 young (SVL $<38 \mathrm{~mm}$ ) and 10 adult (SVL $>42 \mathrm{~mm}$ ) L. cf. kuhlii, 13 adult $A$. nicobariensis, and 19 adult $P$. macrotis (only one female included). I used these four groups in the later analyses.

All specimens of young $L$. cf. kuhlii examined had some food in their stomachs. In most specimens, SCM ranged between 1 and $1.5 \%$ of BM, but the specimens with SCM over $2 \%$ of BM were also abundant and some had SCM even over $3 \%$ of BM (Fig. 1A). In adult $L$. cf. kuhlii, one out of 10 specimens examined had no contents in the stomach. Over $40 \%$ of the specimens had the SCM smaller than $0.5 \%$ of $\mathrm{BM}$, while some had SCM about 2.5 to $3 \%$ of BM (Fig. 1B).
Polypedates macrotis included many specimens with empty stomachs (five out of 19 [26.3\%]), but some specimens had SCM exceeding $3 \%$ of BM (Fig. 1C), although the frequency of occurrence of such individuals was lower than in young $L$. cf. kuhlii.

Four out of $13 \mathrm{~A}$. nicobariensis (30.8\%) also had no stomach contents. In this species, specimens with food in the stomach possessed $\mathrm{SCM}$ between 0 to 1 or 1 to $1.5 \%$ of $\mathrm{BM}$ and no individual had SCM over $2 \%$ of BM (Fig. 1D).

\section{Size relationships of frogs and food items}

The frequency of occurrence of food items in each length-based size class is shown in Fig. 2 . In young $L$. cf. $k u h l i i$, foods with the length smaller than $5 \mathrm{~mm}$ appeared most frequently and occupied about $70 \%$ of the total number of food items. The largest food did not exceed $20 \mathrm{~mm}$ in these young frogs (Fig. 2A). In adult $L$. cf. kuhlii, foods of 5 to $10 \mathrm{~mm}$ in length were most abundant, accounting for over $50 \%$ of the total number. The largest food taken was much larger than in young 


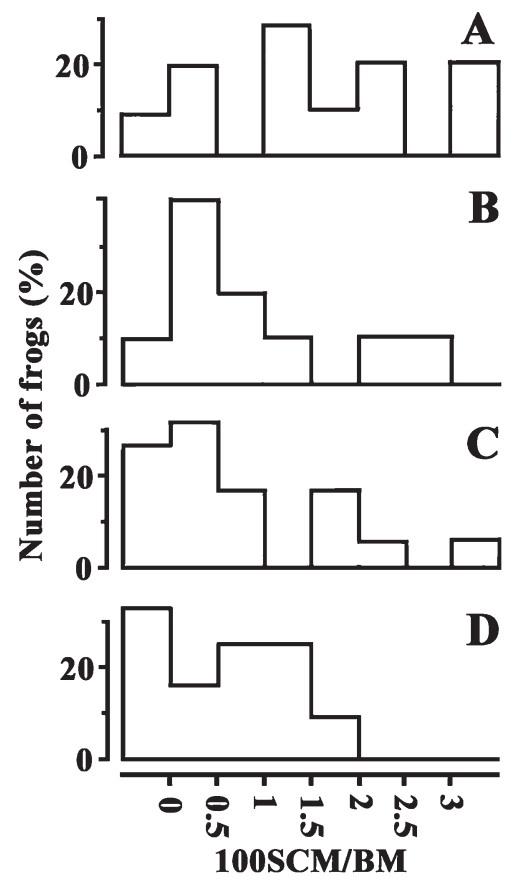

FIG. 1. Variation in the stomach content mass (SCM) relative to body mass (BM) in four groups of frogs (A: young Limnonectes cf. kuhlii; B: adult L. cf. kuhlii; C: Polypedates macrotis; D: Amnirana nicobariensis).

frogs and exceeded $20 \mathrm{~mm}$ in length (Fig. 2B).

In $A$. nicobariensis, foods with the length of 5 to $10 \mathrm{~mm}$ accounted for over $50 \%$ of the total number of items, and smaller foods less than $4 \mathrm{~mm}$ in length were also abundant, accounting for about $40 \%$ of the total. The largest food taken by this species was smaller than $15 \mathrm{~mm}$ (Fig. 2C).

In $P$. macrotis, foods of 5 to $10 \mathrm{~mm}$ occurred most frequently, but they constituted less than $40 \%$ of the total number, and foods of 10 to $15 \mathrm{~mm}$ and of over $20 \mathrm{~mm}$ were also abundant (Fig. 2D). Minute foods with the length smaller than $5 \mathrm{~mm}$ were rarely taken by this species.

As shown in Fig. 3, adult $L$. cf. kuhlii and P. macrotis (except for one female) are about the same size in SVL, and both are slightly larger than adult $A$. nicobariensis. There was a great variation in the size of the food, and

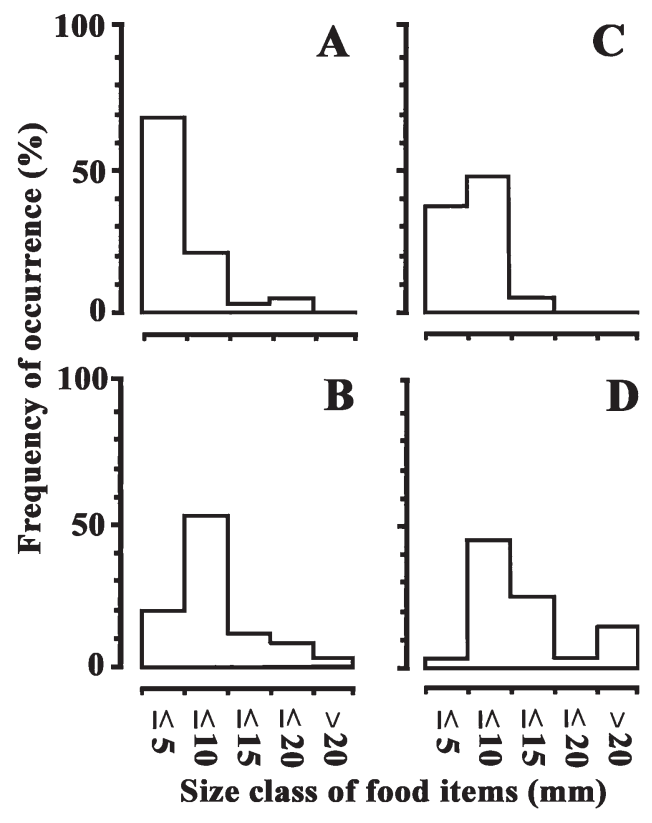

FIG. 2. Variation in the lengths of food items eaten by four groups of frogs. (A: young Limnonectes cf. kuhlii; B: adult L. cf. kuhlii; C: Amnirana nicobariensis; D: Polypedates macrotis).

the comparison of the values between young and adult $L$. cf. kuhlii suggests that the larger frogs eat larger foods. Although $\mathrm{A}$. nicobariensis is significantly larger than young $L$. cf. kuhlii in body size, they did not differ in the size of the food. Consequently, foods of A. nicobariensis are smaller than those of adult $L$. cf. kuhlii.

Except for one $P$. macrotis, all frogs had the mean food length smaller than their mouth width. The one exceptional individual of $P$. macrotis had a large caterpillar in its stomach (Fig. 4). Young and adult $L$. cf. kuhlii and $A$. nicobariensis had similar relative values for the mean food length, all being about $46 \%$ of the mouth width. By contrast, P. macrotis had a mean of $78 \%$. The mean value for this species, however, is not different from those of three other groups, because the variation range was very large in $P$. macrotis. 


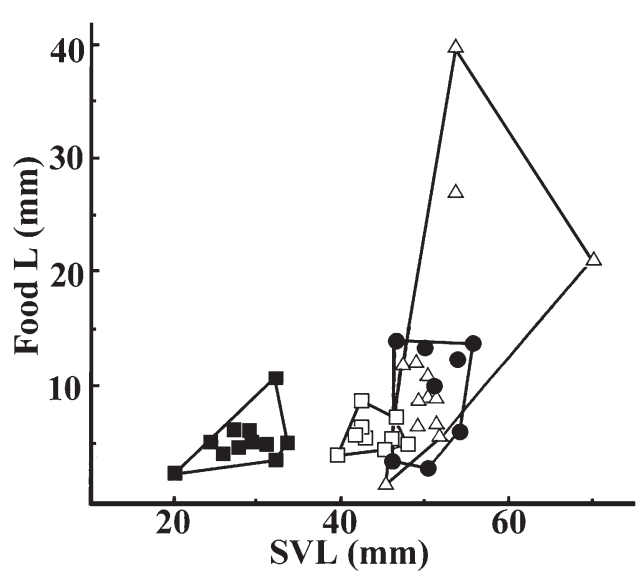

FIG. 3. Relationship of the mean food length to the snout-vent length (SVL) in four groups of frogs. Closed squares: young Limnonectes cf. kuhlii; closed circles=adult Limnonectes $\mathrm{cf}$. kuhlii; open squares: Amnirana nicobariensis; open triangles =Polypedates macrotis.

\section{Composition of foods}

The food items of frogs as revealed by the analyses of stomach contents are shown in Table 2. A total of 178 items were found in the stomachs of 53 frogs of the three species examined, including those without any content. Consequently, about 3.4 items, on an average, were present in each frog. When only frogs with foods in the stomach were considered, about 4.1 items were present. The average number of items in a stomach was largest in young $L$. cf. kuhlii (6.5 per stomach), and was nearly identical in adult $L$. cf. kuhlii and $A$. nicobariensis (4.7). On the contrary, only 1.6 items were present in a specimen of $P$. macrotis.

For each group, the percentage ratio of the number of each food item to the total number was calculated (Table 3 ). When all frogs were combined, ants occupied the largest proportion, accounting for about one-fourth $(25.3 \%)$ of all the food items. This is largely due to the fact that a single particular frog ate a large number of ants. Crickets or grasshoppers, beetles, and spiders ranked next to fourth, but each of their ratios to the total number was smaller than $10 \%$.

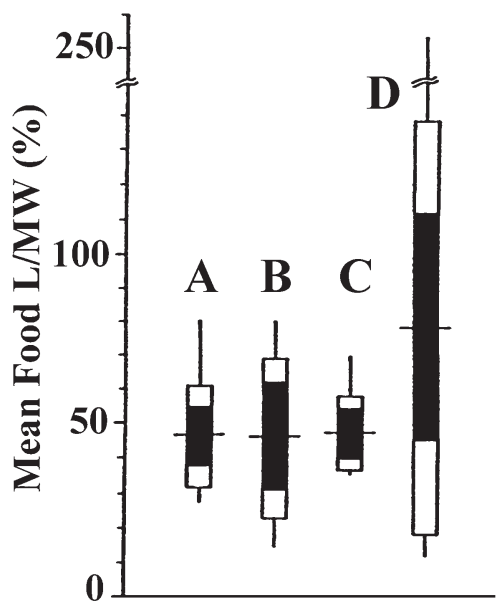

FIG. 4. Variation in the mean food length relative to the mouth width (MW) in four groups of frogs. A: young Limnonectes cf. kuhlii; B: adult L. cf. kuhlii; C: Amnirana nicobariensis; D: Polypedates macrotis. Range, 1SD, and 1SE are given.

\section{Discussion}

It is clear from our results that adult frogs, compared with young, more frequently have either empty stomachs or those with relatively light contents. This may possibly be due to the fact that most of adult frogs were in their breeding seasons; about a half of $\mathrm{A}$. nicobariensis were breeding females with fully matured ovaries and leaving little space for the stomach in the body cavity. It is, however, not probable that the frequent occurrence of empty stomachs in adults is fully attributable to their breeding condition, because breeding season seems to last too long in the tropics for the frogs to endure without taking any food. Occurrences of empty stomachs and, if present, of small number of food items in many $P$. macrotis seem to suggest that this species has a habit of taking foods with a long interval.

The results also show that $L$. cf. $k$ kuhlii feeds on larger foods with advancing age. Amnirana nicobariensis seems to choose smaller foods, while $P$. macrotis tends to take larger foods than L. cf. kuhlii. The mouth width is supposed to have a great meaning in the frog's 


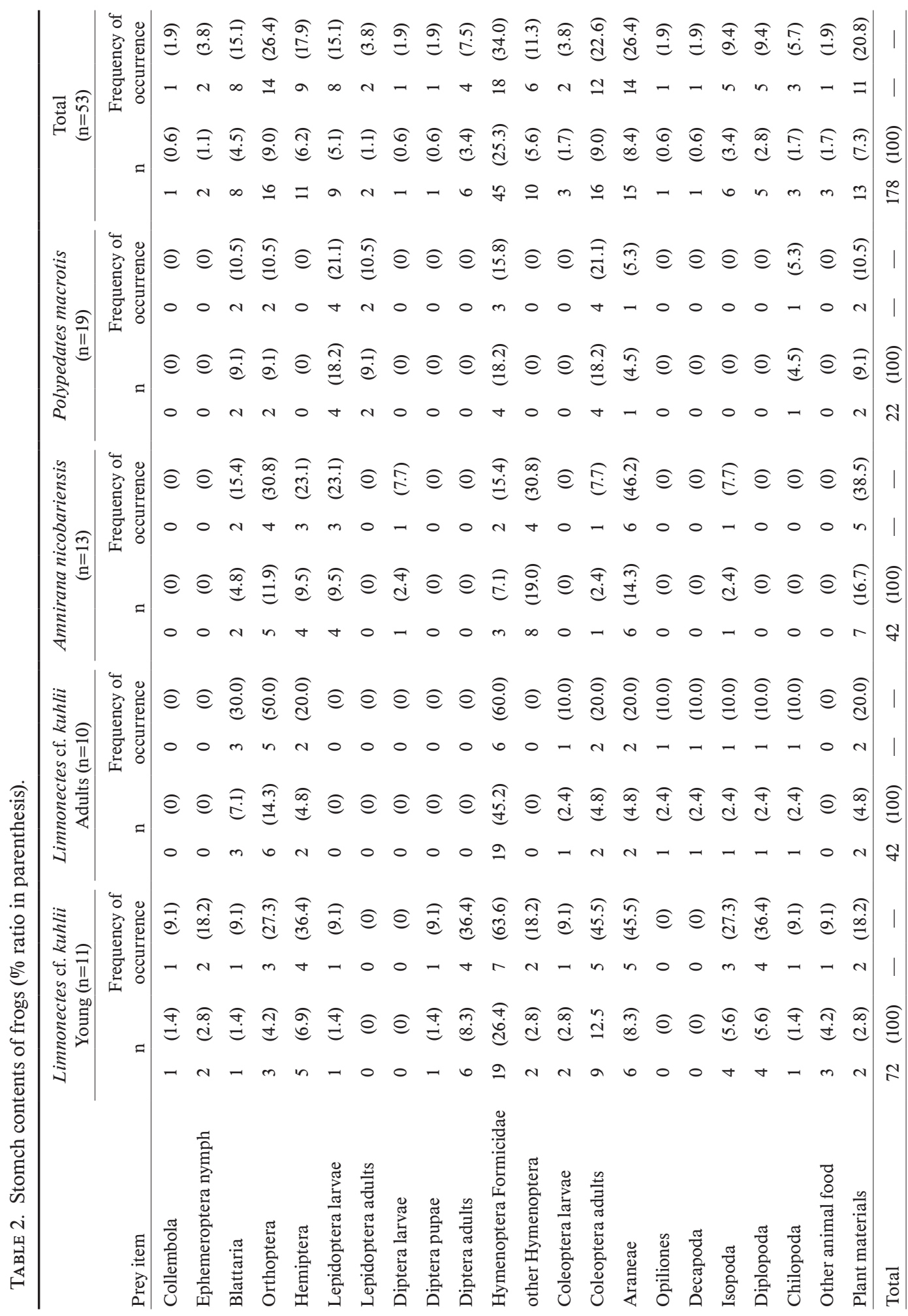


TABle 3. Partitioning of foods (in \%) among three frog species.

\begin{tabular}{lccc}
\hline Food item & $\begin{array}{c}\text { Limnonectes } \\
\text { cf. } \text { kuhlii }\end{array}$ & $\begin{array}{c}\text { Amnirana } \\
\text { nicobariensis }\end{array}$ & $\begin{array}{c}\text { Polypedates } \\
\text { macrotis }\end{array}$ \\
\hline Collembola & 100 & 0 & 0 \\
Ephemeroptera & 100 & 0 & 0 \\
Blatteria & 50.0 & 25.0 & 25.0 \\
Orthoptera & 56.3 & 31.3 & 12.5 \\
Hemiptera & 63.6 & 36.4 & 0 \\
Lepidoptera & 9.1 & 36.4 & 54.5 \\
Diptera & 87.5 & 12.5 & 0 \\
Hymenoptera & 72.7 & 20.0 & 7.3 \\
Coleoptera & 73.7 & 5.3 & 21.1 \\
Araneae & 56.3 & 37.5 & 6.3 \\
Myriapoda & 85.7 & 14.3 & 0 \\
Crustacea & 90.9 & 0 & 9.1 \\
\hline
\end{tabular}

capacity in size of foods (e.g., Toft, 1980). Adult $L$. cf. kuhlii has a head larger than other species, except adult female P. macrotis. Amnirana nicobariensis has a narrow head and the mouth widths of this species were almost completely within the variation range of young L. cf. kuhlii (Matsui, unpublished data; Inger, 1966).

Tibia length might be reflecting the ability of jumping both for escaping from enemies and catching prey animals. Amnirana nicobariensis had the tibia significantly longer than that of young L. cf. kuhlii (Matsui, unpublished data; Inger, 1966), but the mean size of foods taken by them was almost identical. This suggests that the length of the frog's tibia does not necessarily directly correlate to the food length, and that the ability of jumping in relation to nature of foods should be examined not from a quantitative, but from a qualitative point of view.

There were variations in the proportion of each food item among four groups of frogs. In young $L$. cf. kuhlii, ants constituted the largest portion $(26.4 \%)$ and adult beetles ranked next (12.5\%). Adult $L$. cf. kuhlii also took ants even in much larger proportions $(45.2 \%)$, and the second most frequent food was crickets (14.3\%). Contrasting to adult and young $L$. cf. kuhlii, the proportion of ants was small (7.1\%) and instead, that of bees and wasps was the largest in $A$. nicobariensis, although the latter value was not very large $(19.0 \%)$. This species was also characterized by the frequent occurrence of plant materials in the stomach. Spiders were the second most frequent food, and crickets and grasshoppers ranked third in this species. In $P$. macrotis, no particular kind of food occupied high percentages, and each of caterpillars, ants and beetles occupied the same ratio $(18.2 \%)$.

The food items in the stomachs of all four groups of frogs belonged to Blattaria, Orthoptera, Formicidae, adult Coleoptera, and Araneae. Formicidae was found in the stomachs of more than one-third of frogs examined, and each of Orthoptera, adult Coleoptera, and Araneae was also found in about one-fourth of frogs. It should be noted, however, that some other food items, although appearing in relatively high frequencies in some form of frogs, were not found in other forms (Table 2). Hymenoptera other than Formicidae was found in about one-fifth of young $L$. cf. kuhlii and one-third of $A$. nicobariensis, but was not found at all in adult $L$. cf. kuhlii and P. macrotis. Hemiptera was found in about one-third of young $L$. cf. $k$ khlii and in about one-fifth of adult $L$. cf. kuhlii and of $A$. nicobariensis, but was absent in 
$P$. macrotis. In contrast, larval Lepidoptera was limited to one-tenth of $P$. macrotis.

In this way, groups of frogs showed some tendencies in food items consumed. In both young and adults, three-fifths of $L$. cf. kuhlii had ants in their stomachs. Beetles and spiders were also found in nearly half of young $L$. cf. kuhlii, but in adults, these foods were found only in one-fifth. The majority of beetles eaten by this species were harpalid ground beetles and other terrestrial species. Half of adult $L$. cf. kuhlii had crickets in the stomach, but less than one-third of young did so. Unlike other forms, more than one-third of young $L$. cf. kuhlii contained Hemiptera or Diplopoda in their stomachs. In $\mathrm{A}$. nicobariensis, nearly $50 \%$ individuals had eaten spiders, and one-third had Orthoptera or Hymenoptera other than Formicidae. Polypedates macrotis showed simpler food selection; contrasting to 18 kinds of items found in young $L$. cf. kuhlii, only nine kinds of foods were found in this species. Stomachs of about one-fifth of $P$. macrotis contained larval Lepidoptera or adult Coleoptera and about one-sixth had ants, but other foods were taken only sporadically by this species. Of coleopterous insects eaten by $P$. macrotis, one-fourth was Elateridae and the remaining three-fourths were Scarabaeidae.

The above tendencies in the relative frequencies of food items in the four groups of frogs seem to reflect differences in morphology and ecology of each form. Thus, young $L$. cf. kuhlii tends to feed on many kinds of small terrestrial invertebrates just at the bank of the stream. Many insects, especially ants, visit the bank for seeking water and would be easily caught by this species. Because adults, especially males, of $L$. cf. kuhlii have a broad head, they can feed on larger prey such as grasshoppers. On the contrary, narrowmouthed and long-limbed $A$. nicobariensis seems to hunt small crickets, bees and wasps, and spiders among grasses. Arboreal P. macrotis is thought to find large caterpillars and beetles on trees. It may feed on ants moving on the tree, but not in great quantities, and after succeeding in catching a small number of foods, this species seems to rest before hunting again.

It is also to be noted that termites were never found in the stomachs of frogs here examined. Because some specialized termite feeding microhylid frogs, such as Kaloula baleata (Inger, 1966), were also present in the area surveyed, there may probably be a segregation in food selection between these specialized forms and the more generalized species including the three species examined.

In conclusion, there exist too many complex ecological factors between prey and predator, and, of course, a simple examination of limited data should be made with great care. It may, however, be postulated that some treeeating insects, such as lepidopteran caterpillars, and scarabaeid and elaterid beetles, could be regarded as harmful to plants, but that some non-insect animals, such as spiders and myriapodes, could be regarded as useful in that they consume insects including pest species. Both of these two kinds of small animals were found to be frequently eaten by frogs. Although the present data suggest that the proportion of harmful invertebrates was larger than that of useful invertebrate predators, further analyses are needed to confirm such dietary pattern in those frogs.

Thus, the data obtained here are too meager to draw general conclusions about prey/ predator relationships of tropical invertebrates and frogs, and it is as yet not clear to which degree frogs contribute in controlling the number of forest insects. It is, however, obvious from the results of the present investigation that frogs act as an effective natural enemy for many invertebrates including possible forest pests, such as Lepidoptera and Coleoptera. Presently unimportant insect species could become important pests in the course of reforestation (e.g., Nang'ayo et al., 1993), and this type of investigation, when made in greater extent with exact identification of prey items at the species level, will undoubtedly provide us with important knowledge about the balance of predator/prey rela- 
tionships in the tropical rain forest that is ultimately useful in conducting forest pest control.

\section{ACKNOWLedGements}

I would like to express high admiration and appreciation for the Malaysian organizations concerned for their kind considerations in approving my research and for their assistance given to me during my research period. Special thanks are extended to Mr. K. M. Mastan of the Forest Department of Sabah, who kindly understood and supported the research. The research was carried out in collaboration with members of Entomological Section of the Forest Research Centre, Sepilok, Sandakan. I thank all of them for their kind cooperation. I cordially thank Messrs. P. K. Cassels, F. Liew, T. K. Chong and all other personnel of Sabah Softwoods Sdn. Bhd. for kind accommodation and valuable help in conducting survey at Brumas Plantation. Thanks are due to the late Prof. T. Hidaka for giving me an opportunity to conduct present research and to Prof. T. Hikida and Dr. K. Sakurai for warm companionship and help during the survey. I thank two anonymous reviewers for improving the earlier version of manuscript and T. Johnson for reviewing English text. Field trips were made possible by grants from the Monbusho to T. Hidaka (Field Research, 60041037).

\section{Literature Cited}

Hirai, T. and Matsui, M. 1999. Feeding habits of the pond frog, Rana nigromaculata, inhabiting rice fields in Kyoto, Japan. Copeia 1999: 940-947.

Hirai, T. and Matsui, M. 2000a. Ant specialization in diet of narrow-mouthed toad, Microhyla ornata, from Amamioshima Island of the Ryukyu Archipelago. Current Herpetology 19: 27-34.

Hirai, T. And Matsui, M. 2000b. Feeding habits of the Japanese Tree Frog, Hyla japonica, in the reproductive season. Zoological Science
17: 977-982.

Hirai, T. and Matsui, M. 2001. Attempts to estimate the original size of partly digested prey recovered from stomachs of Japanese anurans. Herpetological Review 32: 14-16.

Hirai, T. and Matsui, M. 2002. Feeding ecology of Bufo japonicas formosus from the montane region of Kyoto, Japan. Journal of Herpetology 36: 719-723.

Hocking, D. J. AND BabBitt, K. J. 2014. Amphibian contributions to ecosystem services. Herpetological Conservation and Biology 9: $1-17$.

INGER, R. F. 1966. The systematics and zoogeography of the Amphibia of Borneo. Fieldiana: Zoology 52: 1-402.

INGER, R. F. 1969. Organisation of communities of frogs along small rain forest streams in Sarawak. Journal of Animal Ecology 38: 123-148.

INGER, R. F. 1985. Tadpoles of the forested regions of Borneo. Fieldiana: Zoology. New Series 26: $1-89$.

Inger, R. F. AND Bacon, J. P. 1968. Annual reproduction and clutch size in rain forest frogs from Sarawak. Copeia 1968: 602-606.

INGER, R. F. AND GREENBERG, B. 1966. Ecological and competitive relations among three species of frogs (genus Rana). Ecology 47: 746-759.

Matsui, M. 1979. Amphibians from Sabah I. Systematic and natural history notes. Contributions from the Biological Laboratory, Kyoto University 25: 303-346.

Matsui, M. 1982. Amphibians from Sabah II. Acoustic characteristics of three common anuran species. Contributions from the Biological Laboratory, Kyoto University 26: 123-129.

Matsui, M. 1986. Three new species of Amolops from Borneo (Amphibia, Anura, Ranidae). Copeia 1986: 623-630.

Matsui, M. 2006. Anuran inventory in SabahPast and future. Current Herpetology 25: 1-14.

Matsui, M., Shimada, T., ANd Sudin, A. 2010. A new species of Meristogenys from Sabah, Borneo (Amphibia, Anura, Ranidae). Zoological Science 27: 61-66.

Matsui, M., Shimada, T., And Sudin, A. 2013. A new gliding frog of the genus Rhacophorus from Borneo. Current Herpetology 32: 112-124. 
Matsui, M., Shimada, T., And Sudin, A. 2014a. First record of the tree-frog genus Chiromantis from Borneo with the description of a new species (Amphibia, Rhacophoridae). Zoological Science 31: 45-51.

Matsui, M., Nishikawa, K., and Yambun, P. 2014b. A new Leptolalax from mountains of Sabah, Borneo(Amphibia, Anura, Megophryidae). Zootaxa 3753: 440-452.

Nang'Ayo, F. L. O., Hill, M. G., Chandi, E. A., Chiro, C. T., Nzeve, D. N., And Obiero, J. 1993. The natural environment as a reservoir for the Lager Grain Borer Prostephanus trun- cate (Horn) (Coleoptera: Bostrichidae) in Kenya. African Crop Science Journal 1: 39-47.

ToFt, C. A. 1980. Feeding ecology of thirteen syntopic species of anurans in a seasonal tropical environment. Oecologia 45: 131-141.

ToFt, C. A. 1981. Feeding ecology of Panamanian litter anurans: Patterns in diet and foraging mode. Journal of Herpetology 15: 139-144.

Accepted: 19 June 2016 